\title{
Os conteúdos da programação radiofônica internacional do Brasil e da Espanha*
}

\author{
Venerando Ribeiro de Campos**
}

\begin{abstract}
Resumo
Trabalho de pesquisa que faz uma comparação das programações e das notícias de duas emissoras de radiodifusão internacional, - Rádio Nacional do Brasil e Rádio Exterior da Espanha -, com o objetivo de comprovar se as semelhanças e as diferenças de estruturação de suas programações e dos conteúdos de suas notícias possuem relação direta com suas funções e intenções comunicativas.

Palavras-chave: rádio, programação, programa e notícia.
\end{abstract}

\section{Introdução}

Esta pesquisa se propõe a fazer um estudo comparativo da radiodifusão internacional de dois países - Brasil e Espanha - utilizando o material veiculado, em idioma espanhol, por suas respectivas emissoras de ondas curtas - Rádio Nacional do Brasil e Rádio Exterior da Espanha - em seus programas diários dirigidos à América do Sul.

O material de análise é composto por dois tipos diferentes mas não excludentes de dados: a programação radiofônica e a notícia. Por um lado, programação radiofônica, para Muñoz y Gil (1987, p. 46), "é a previsão dos programas que vão ser emitidos durante um tempo determinado através de uma emissora de rádio"; e, por outro lado, notícia radiofônica, desde um ponto de vista tradicional, "é uma maneira de refletir a realidade sem juízo de valor e com o máximo grau de objetividade possível (Cebrián Herreros, 1992, p.120). Van Dijk

* Síntese da tese de doutorado intitulada Los contenidos de la programación radiofónica exterior de Brasil y Espanha defendida pelo autor na Faculdade de Ciências da Informação da Universidade Complutense de Madri, em novembro de 1998.

** Professor da Faculdade de Comunicação e Biblioteconomia da UFG, Doutor em Comunicação pela Universidade Complutense de Madri.

Comun. Inf., v. 3, n. 1, p. 13-26, jan./jun. 2000 


\title{
14
}

(1990), autor que estudou a notícia como um tipo de discurso, acrescenta que, pelo menos intencionalmente, a notícia está concebida como um relato puro e realista dos fatos e opiniões que aparecem na realidade. Rodrigo Alsina (1989, p. 184) resume as definições que se dão para o termo notícia em dois grandes grupos: "Por um lado estariam os que defendem a concepção da notícia como espelho da realidade. Por outro lado, a notícia seria concebida como construção da realidade".

Em ambos casos, como é fácil perceber, a notícia sempre se apresenta como um substituto da realidade. Por isso, nesta pesquisa, tanto a notícia como a programação são consideradas representações da realidade, ao representarem algo que se converte em símbolos, istoé, em elementos que congregam um significado. Isso, a princípio, parece evidente em relação às notícias, vistas mais facilmente como informação, mas não em relação à programação. Esse entendimento permite ver esta como um resultado dependente do mesmo processo de produção daquela e, portanto, capaz também de expressar pelo menos alguns significados e idéias gerais. Krippendorff (1990, p. 252)) assim justifica esse ponto de vista:

\begin{abstract}
"Se toda investigação científica está motivada pelo desejo de conhecer ou de entender melhor uma porção do mundo real, uma análise de conteúdo deve se interessar por duas espécies de realidade: a realidade dos dados e a realidade do que o pesquisador quer conhecer. Na análise de conteúdo estas duas realidades não se superpõem, não são coincidentes, de modo que o pesquisador terá que encontrar a maneira de considerar os dados que estão em condições de analisar como manifestações simbólicas ou indicadores dos fenômenos que lhe interessam".
\end{abstract}

O método comparativo, nesta pesquisa, será utilizado para contrastar as duas instituições - REE-Rádio Exterior da Espanha e RNB-Rádio Nacional do Brasil - sob duas perspectivas: a estrutura de suas programações (duração, organização programática, organização interna dos programas, tratamentos utilizados para atrair a atenção da audiência) e a estrutura das notícias veiculadas pelas duas emissoras (segmentos básicos da estruturação discursiva, categorias semânticas, indicadores pragmáticos, temas, intenção e intencionalidade no discurso).

Comun. Inf., v. 3, n. 1, p. 13-26, jan./jun. 2000 
Para estudar a programação e a notícia, escolhemos como suporte a rádio internacional, um tipo de rádio que teve importância muito grande durante e depois da segunda Guerra Mundial, até a queda do muro de Berlim, em 1989. A rádio internacional hoje é considerada, em zonas de paz, um serviço para os assuntos e interesses dos Estados em suas relações internacionais. Um serviço cujas orientações políticas estão dinamizadas pela política exterior do Estado. $\mathrm{Ou}$, em outros termos, a rádio internacional difunde, sempre ou quase sempre, uma imagem estatal, segundo a interpretação de estatal que faz o grupo que em cada momento ocupe o poder.

Além disso, a escolha das duas emissoras se justifica principalmente porque Brasil e Espanha apresentam entre si alguns fatores de identidade que criam uma base sólida para um trabalho de investigação comparativo: são dois países política e economicamente potentes, e duas jovens democracias que seguem, cada uma a seu modo, tendo marcas de seus regimes ditatoriais - ainda que se encontrem em situação muito diferente no panorama mundial - e também interesses econômicos, culturais e políticos na América do Sul; e suas duas emissoras internacionais, no idioma espanhol, transmitem programas radiofônicos especialmente dirigidos à audiência desta zona latino-americana.

Como se sabe, o rádio é um meio de comunicação de massas muito importante, para qualquer tipo de audiência. Na emissão e na recepção é o meio mais barato entre todos os outros meios. $\mathrm{O}$ rádio é um veículo de distribuição de notícias, fonte de entretenimento, serve de companhia, instrumento de expansão da paz, importante veículo de apoio à educação, e também importante como veículo de propaganda, principalmente a rádio internacional ou exterior, onde a propaganda é mais sutil.

Neste sentido, as rádio internacionais são emissoras públicas que têm, geralmente, três grandes objetivos: a criação de uma determinada imagem do país emissor no exterior, a transmissão de propaganda política e ideológica, e propaganda de credos religiosos.

Para esta pesquisa, a partir da consideração dos dados escolhidos como objeto de estudo - a estrutura da programação e das notícias em ambas as emissoras - se definiu que a finalidade é fazer uma comparação entre alguns aspectos do discurso programático e noticioso de dois sistemas de radiodifusão internacional, o espanhol e

Comun. Inf., v. 3, n. 1, p. 13-26, jan./jun. 2000 
o brasileiro. Nosso interesse não foi só determinar as especificidades das programações e notícias, comparando suas características estruturais e semânticas, mas demonstrar a existência de uma relação entre ao menos algumas dessas especificidades e as intenções significativas do emissor, no caso as duas emissoras estatais responsáveis pela produção dos programas e das notícias.

Este estudo foi realizado, em primeiro lugar, baseado em estudos e teorias sobre a organização e estruturação da programação e da notícia radiofônicas, que foram tomados como guias de orientação com o propósito de descrever tanto a programação das duas emissoras como dos textos noticiosos. Sobre este aspecto mereceram especial atenção os estudos de alguns teóricos espanhóis e brasileiros que investigaram a programação como um complexo fenômeno comunicacional mediante o qual se definem, selecionam, ordenam e estruturam os programas como unidades básicas da emissão radiofônica. Entre eles, os estudiosos mais destacados são Faus Belau (1974), Cebrián Herreros (1992), Martí i Martí (1990), Swetlana (1985), Merayo Pérez (1992), etc.

Em segundo lugar, a análise propriamente lingüística dos textos, a orientação foi buscar sobretudo nas reflexões teóricas e metodológicas que nos apresentam Van Dijk (1990) acerca da notícia como um tipo particular de discurso jornalístico, e em estudos sobre a interpretação de notícias jornalísticas por diversos autores, como, por exemplo, Rodrigo Alsina (1989), Fontcuberta, e Velázquez (1987). Entretanto, nenhum dos estudos é seguido rigorosamente em sua totalidade. Devido principalmente às diferenças de propósito e meio de massa analisado, a aplicação pura de um deles já seria, certamente, uma tarefa inadequada e desnecessária.

De qualquer maneira, convém destacar que, ainda que esses estudos se refiram à notícia impressa e não à radiofônica, enfatizam os aspectos estruturais e lingüísticos dos textos, enfoque que coincidiu com o que se buscava para a análise.

Portanto, a análise que se realizou não segue um modelo já estabelecido e próprio para o discurso radiofônico. Como se pode concluir com base na bibliografia especializada, os estudos sobre a estruturação do discurso por rádio encontram-se ainda em sua fase inicial de gestação. Pode-se dizer que não há modelos já definidos e disponíveis, possivelmente pelas dificuldades próprias desse tipo de discurso.

Comun. Inf., v. 3, n. 1, p. 13-26, jan./jun. 2000 
A orientação teórica que considerei leva em consideração o texto noticioso não somente como uma estrutura que se pode determinar, mas como um discurso ou texto, isto é, uma prática social específica, entre sujeitos sociais definidos, em um tempo e espaços determinados, e que, além de um sentido, tem também intenções que estão na base de sua própria estruturação. As notícias analisadas foram vistas, entạ̃o, como um tipo particular de discurso que apresenta certas semelhanças com o de outros meios de comunicação. A imprensa, por exemplo, tem, sem dúvida, suas próprias especificidades.

No processo de produção das notícias, o sujeito que informa escolhe os fatos da realidade, constrói o texto das notícias, e nele expressa, eventualmente, suas próprias opiniões e comentários. Essas ações correspondem a dois graus de interpretação da realidade que se oferece como matéria informativa. Há a interpretação que se manifesta claramente no texto, como categoria semântica discursiva, e há também aquela que se encontra implícita nos textos, ao que se denomina interpretação implícita ou intencionalidade do emissor; portanto, somente podemos inferi-la mediante a análise dos recursos sintáticos, semânticos e pragmáticos que são utilizados na construção do texto.

\section{Metodologia}

Depois de definir o objeto de estudo, o marco teórico, os objetivos e as hipóteses, procurei uma metodologia que pudesse atender a meus fins investigativos. Depois de várias buscas, a análise de conteúdo foi escolhida como a mais adequada, principalmente por sua grande utilização nos estudos da significação no âmbito das ciências sociais, onde se inclui, obviamente, a comunicação de massa. Considerei a análise de conteúdo, nesta investigação, como adequada para a análise dos aspectos lingüísticos que permitem destacar os tópicos, os temas e a intencionalidade e, além disso, para descrever a estrutura da programação radiofônica.

Esta pesquisa, que se caracteriza como uma análise interpretativa dos conteúdos das duas programações, desde sua concepção inicial pretendia ir além da comparação quantitativa dos dados, intenção que também está de acordo com o método proposto por Van Dijk. Sua análise faz uma crítica à análise rotineira baseada no quantitativo. Além disso, convém destacar, uma vez mais, a já reiterada aplicação dessa

Comun. Inf., v. 3, n. 1, p. 13-26, jan./jun. 2000 


\section{8}

metodologia de análise de conteúdo nos estudos sobre comunicação, desde o emissor ao receptor, passando pelos códigos, e ainda que sua eficácia esteja reconhecida em setores diversos, a comunicação de massa continua constituindo seu principal campo de utilização (Van Dijk, 1990).

A análise de conteúdo, como se sabe, se limitou de uma maneira quase exclusiva à análise das mensagens escritas e gravadas. Particularmente, é a mensagem impressa a que oferece ao pesquisador as melhores condições de acessibilidade e manipulação, já que está disponível na superfície do papel. Costuma-se dizer que a análise de conteúdo se vê afetada por um grave desequilíbrio de crescimento porque só a do meio impresso se desenvolveu normalmente. A do rádio, do cinema e da televisão sofre de atrofia. A carência de estudos é outra boa razão para minha tentativa de aplicação da metodologia de análise de conteúdo ao material do meio rádio. Para facilitar sua análise, a mensagem sonora foi transcrita para a linguagem escrita. E acredito que recolhê-la, transcrevê-la e estruturála é uma parte importante deste estudo.

Vale recordar que esta é uma análise sobre a programação e o discurso da notícia. Conceber a notícia como discurso é o mesmo que ter em conta um processo específico de interação social, no qual o sujeito emissor das notícias tem também algumas características específicas: ele é, em primeiro lugar, um emissor coletivo, quer dizer, sua suposta singularidade representa, pelo menos em linhas gerais, os interesses da empresa e daqueles que falam aos ouvintes, os fabricantes de notícias nos termos de Van Dijk (1990), Villafañé, Bustamante e Prado (1987). Em segundo lugar, esse emissor é alguém que, interpretando os fatos da realidade, constrói subjetivamente as notícias e as transmite para sua audiência, como se elas fossem o mais fiel reflexo da realidade.

Partindo dessa concepção construtivista da notícia e para chegar aos objetivos desta pesquisa, os textos noticiosos foram analisados segundo um procedimento metodológico que leva em conta, primeiramente, três diferentes níveis ou dimensões da descrição textual: os níveis mais tradicionais da gramática, os assim chamados níveis sintático e semântico do texto e, por último, um mais novo nível textual, o pragmático. Esse nível descritivo se relaciona mais diretamente como uso social da língua, buscando descrever seu modo de utilização por parte dos falantes. Assim, se sai da consideração isolada das estruturas

Comun. Inf., v. 3, n. 1, p. 13-26, jan./jun. 2000 
lingüísticas para a situação comunicativa, onde se encontram, além de outros elementos, os usuários da língua.

Num segundo momento, a análise propõe a possibilidade de definir os temas das notícias sobre a base do conhecimento propiciado pela descrição dos textos a partir da tripla perspectiva indicada. $O$ passo seguinte trata da interpretação que o discurso noticioso pretende fornecer à sua audiência, destacando, além disso, a intencionalidade com a qual o emissor construiu suas notícias (difundir uma ideologia, vender uma imagem positiva do país, etc).

O modelo lingüístico explicativo que apliquei e que derivou das precedentes considerações de caráter teórico e metodológico tem três características básicas:

Parte, primeiramente, da idéia de que o discurso da notícia na radiodifusão internacional tem suas próprias especificidades, nascidas sobretudo dos interesses das emissoras, públicas e estatais, e das imposições mais genéricas do canal, como são as de caráter político que inspiram as atuações midiáticas em qualquer rádio, em especial nas internacionais.

Utiliza, em segundo lugar, procedimentos descritivos e técnicas de segmentação usuais na análise de conteúdo: programas, enunciados, frases, etc. E, por último, pretende formular inferências a respeito do conteúdo semântico das notícias, de modo especial sobre seus temas e a interpretação geral que se pode dar ao conjunto da amostra, que é o que em grande medida define a intencionalidade do emissor.

O modelo de análise assim concebido é composto de cinco partes distintas, correspondentes às três primeiras: a análise das unidades sintáticas, semânticas e pragmáticas, que foram consideradas de importância fundamental para possibilitar o acesso à interpretação semântica dos textos. As duas últimas partes expressam dois momentos distintos do exercício de interpretação: a definição dos temas e da intencionalidade do emissor.

No que se refere à técnica geral da comparação, baseei-me em Duverger (1962), porque mesmo que seja clássico, continua sendo um autor fácil e claro em sua exposição metodológica. Para esse autor, dois problemas importantes se apresentam segundo o grau de analogia das coisas que se quer comparar. O primeiro está relacionado com os problemas da estrutura e tipologia do texto e, o segundo, com o problema do contexto em que se insere. Quanto à estrutura, há que se

Comun. Inf., v. 3, n. 1, p. 13-26, jan./jun. 2000 
considerar dois aspectos: em primeiro lugar, que os fatos comparados devem ter fisionomias gerais próximas e, em segundo lugar, que seus graus de complexidade não devem ser muito distintos. Quando as estruturas e as fisionomias são muito distintas, a comparação não terá validade. O método, pelo exposto, serve muito bem para comparar instituições e funções, que é o que tentei fazer.

Assim, comparei duas instituições - a Rádio Exterior da Espanha e a Rádio Nacional do Brasil - sob duas perspectivas: a estrutura de suas programações e a estrutura da notícia. Na estrutura da programação: a duração, a organização programática, a organização interna dos programas, os tratamentos utilizados na realização dos programas e os recursos utilizados para atrair a atenção da audiência; e na estrutura das notícias: os segmentos básicos de estruturação discursiva, categorias semânticas, indicadores pragmáticos, temase, principalmente, a intenção dos emissores internacionais.

Para a análise foram selecionadas as programações das duas emissoras emitidas para a América do Sul ${ }^{1}$, em idioma espanhol. Aleatoriamente, as amostras para análise foram coletadas nos períodos de 27 de abril a 01 de maio de 1993, em Madri, e de 15 a 21 de novembro de 1994, em Brasília. Foram 28 horas de programação da emissora espanhola, ou seja, da zero hora às 4 horas da madrugada, de segunda a domingo, horário de maior audiência. Da emissora brasileira, foram 9 horas e 20 minutos, das 10 horas às 11 horas e 20 minutos da manhã, também de segunda a domingo. Para a análise foram selecionados os programas da uma às 2 horas da madrugada da rádio espanhola, de segunda a sexta-feira, totalizando 300 minutos. Da emissora brasileira foi analisado o programa veiculado também de segunda a sexta-feira, totalizando 320 minutos. No que se refere às notícias, foram analisadas 82 da REE ( 52 puras, 14 boletins nacionais, 16 boletins internacionais e 5 comentários). E da RNB foram analisadas todas as notícias veiculadas no horário: 59 notícias puras, sobre temas nacionais.

\section{Resultados e conclusões}

Quanto aos principais resultados alcançados nesta pesquisa, podese afirmar que, para atingir seus objetivos, cada país adotou uma estratégia de programação distinta, diferença que considero de grande relevância.

Comun. Inf., v. 3, n. 1, p. 13-26, jan./jun. 2000 
Ainda que as duas emissoras não façam transmissões de seus programas ao vivo, no que se refere ao tratamento do relato a rádio espanhola utiliza o texto misto, no qual uma parte é emitida ao vivo desde o estúdio e a outra gravada com antecedência através de boletins, entrevistas ou reportagens. A emissora brasileira, por sua vez, grava sempre sua programação com antecedência.

Em relação às técnicas de valorização, na emissora brasileira não há nenhum tipo de hierarquização por importância das notícias, e também não há tratamento em profundidade. Na emissora espanhola, ao contrário, os fatos mais importantes vêm em primeiro lugar e são ampliados posteriormente por meio de boletins. Além disso, a reiteração, em parte pelas características da mensagem radiofônica e em parte pela produção de sentido, é muito utilizada. $\mathrm{Na}$ emissora brasileira, por sua vez, não se verificou nenhum caso de repetição de notícias.

$\mathrm{Na}$ emissora espanhola a valorização foi, em primeiro lugar, em função da procedência: valorizam-se mais as notícias nacionais e menos as internacionais. Em segundo lugar, em função do conteúdo: dá-se mais ênfase às notícias sobre política, economia e cultura do que sobre esportes, por exemplo. E, finalmente, quanto aos gêneros informativos, valorizam-se muito mais a notícia estrita e o boletim, e menos o comentário e a entrevista.

Outra diferença entre as duas programações é que a emissora espanhola emite informações sobre fatos relacionados diretamente à realidade e aos interesses da audiência. Da participação dos repórteres, correspondentes e enviados especiais, além dos protagonistas do acontecimento, resulta uma programação mais atualizada.

Pelos conteúdos analisados, as duas programações internacionais podem ser classificadas como constituintes do modelo programático tradicional, que tem como base a oferta de programas variados, com o fim de informar, entreter e manter o contato emissor/canal/receptor. Quanto à estrutura, as programações se enquadram no tipo mosaico, que se caracteriza por programas isolados e colocados uns atrás dos outros, com maior ou menor coerência (Martí i Martí, 1990).

O modelo da Rádio Exterior da Espanha é o que, segundo os resultados, tem melhores condições de alcançar a audiência internacional. Esse modelo permite à emissora oferecer, dentro do espaço horário, pelo menos dois tipos de programas diferentes a cada

Comun. Inf., v. 3, n. 1, p. 13-26, jan./jun. 2000 


\section{2}

hora. A Rádio Nacional do Brasil, por seu lado, adota um modelo diferente, mas também convencional, que combina notícia com música. Em resumo, o conteúdo mais importante da programação das duas emissoras é o informativo, ainda que modelado segundo a personalidade do emissor.

Passando à análise dos conteúdos informativos, cabe destacar que a concepção de notícia que lhes serve de base é a que vê a notícia como uma construção da realidade, segundo o ponto de vista dos sujeitos que a produzem. Assim, nesta análise, o elemento contextual que requer importância é o sujeito que informa, isto é, a empresa pública estatal de radiodifusão. Sua visão peculiar sobre os fatos e sua intencionalidade informativa foram analisados com base em três indicadores pragmáticos: o conteúdo e atualidade da informação, e as atitudes subjetivas dos informadores.

A partir do ponto de vista da informação radiofônica, dois critérios têm importância no processo de escolha dos fatos: 1) devem ser recentes e atuais; 2) devem referir-se ao "mundo presente" dos ouvintes, ou seja, ao seu universo de interesse.

As notícias da Rádio Nacional do Brasil não se referem a fatos e acontecimentos recentes e também não parecem pertencer ao "mundo presente" dos ouvintes. Por esta razão, seus conteúdos se apresentam quase sempre como possibilidades, previsões, intenções, desejos, idéias ou simplesmente opiniões e não como informações constatativas.

As notícias brasileiras, em seu conjunto, se referem tão somente a medidas e ações do governoe da administração pública, ou, na maioria, a fatos e temas das esferas empresarial, econômica, tecnológica e científica do país. $\mathrm{O}$ "mundo presente" das notícias brasileiras tem em verdade dimensões muito reduzidas e se identifica principalmente com os interesses propagandísticos do próprio governo do país.

O "mundo presente" das notícias espanholas, ao contrário, coincide muito mais com o interesse dos ouvintes, pois os informativos da Rádio Exterior da Espanha tratam com grande objetividade o que de mais importante e atrativo ocorre no dia-a-dia do mundo e, por isso, satisfazem aos interesses dos receptores.

$\mathrm{O}$ imediatismo da informação se apresenta, portanto, como a característica de diferenciação mais notável entre os dois discursos informativos. Ainda que seja necessário destacar que nenhuma das duas emissoras atinge, realmente, o ideal do imediatismo típico da

Comun. Inf., v. 3, n. 1, p. 13-26, jan./jun. 2000 
mensagem radiofônica, deve-se afirmar que as informações da Rádio Exterior da Espanha, além de mais objetivas, são muito mais atualizadas que as da Rádio Nacional do Brasil.

No âmbito da emissora brasileira, a análise dos tempos verbais e expressões temporais denuncia a ausência de atualidade de suas informações e mostra que a emissora tenta dissimular a falta de imediatismo de suas notícias, utilizando diferentes estratégias para construir efeitos semânticos de atualidade. São quatro as estratégias principais que utiliza:

1) indefinição do tempo de referência dos fatos e acontecimentos narrados;

2) uso do tempo presente do indicativo, como presente histórico e habitual, com a função exclusiva de expressar o permanente e o genérico;

3) o emprego de palavras e expressões que, ainda que se refiram ao presente, o concebem como um tempo de duração indefinida ou muito ampla para a informação radiofônica;

4) e, finalmente, o mais interessante, a utilização particular que faz do tempo futuro, convertendo-o no espaço temporal de realização de fatos que se apresentam na atualidade tão somente como desejos, idéias.

A análise das formas lingüísticas que indicam as atitudes subjetivas dos informadores não faz mais que confirmar as distinções até aqui apontadas. Agora é necessário considerar a interpretação que cada emissora, através de seu discurso, tenta transmitir à audiência.

A análise das notícias deixa claro que tanto a emissora espanhola como a emissora brasileira seguiram um procedimento semelhante, evitando expressar, mediante palavras, suas próprias opiniões e juízos sobre acontecimentos narrados, ou seja, ambas as emissoras utilizaram muito escassamente a categoria semântica da interpretação explícita. Mas, de qualquer maneira, fizeram a interpretação dos fatos noticiosos, deixando seus pontos de vista implícitos nos textos.

A análise dessa visão sobre a intencionalidade deixa claro que a atuação informativa das duas emissoras é diferente uma da outra. Enquanto que a Rádio Exterior da Espanha obedece aos parâmetros informativos impostos pelo discurso geral da rádio, a emissora brasileira os ignora, procurando tão somente atingir as finalidades que

Comun. Inf., v. 3, n. 1, p. 13-26, jan./jun. 2000 
derivam de seus próprios interesses a respeito de vender uma imagem favorável do Brasil como um país que tem um grande futuro. Este aspecto adquire na análise uma importância fundamental, porque se converte na base para o estabelecimento e justificativa das demais diferenças.

Comparando os discursos das duas emissoras, conclui-se que a intencionalidade de cada uma delas é o fator principal que determina os marcos mais característicos das notícias. Pelos diferentes resultados expostos nesta pesquisa, acredito que, desde o ponto de vista da informação radiofônica, a programação da Rádio Exterior da Espanha é mais eficaz em seus objetivos. Neste sentido, destaco os seguintes pontos:

a) Emite uma programação que tem como finalidade atender aos interesses de variados grupos de ouvintes. Seu Serviço Mundial em Espanhol está no ar as 24 horas do dia, o que possibilita uma oferta constante de informações de atualidade para o ouvinte. São 91 horas diárias para as várias zonas do mundo. A programação da Rádio Nacional do Brasil, ao contrário, por ter uma duração curta, exige que o ouvinte ligue o seu receptor em um horário fixo, que é no início da manhã, no caso da programação emitida para América do Sul.

b) Os programas de atualidade da Rádio espanhola cobrem uma variedade muito grande de temas, principalmente os culturais.

c) A variedade de gêneros informativos utilizados pela emissora espanhola possibilita a emissão de opinião nos boletins, entrevistas, reportagens e comentários, ainda que nem sempre essa possibilidade encontre plena realização, seguramente por dar prioridade aos aspectos fundamentalmente informativos. Por sua parte, a programação da Rádio Nacional do Brasil emite somente o que estava decidido pelos produtores, sem a participação dos protagonistas dos fatos, ou seja, que se nutre de fontes secundárias, resultando uma informação distanciada de credibilidade.

d) A rádio espanhola conta quase sempre com a participação de correspondentes, enviados especiais e repórteres para as coberturas internacionais e nacionais, o que lhe permite oferecer uma informação muito próxima da realidade. Além disso, como aparato técnico e de pessoal, a emissora está em condições

Comun. Inf., v. 3, n. 1, p. 13-26, jan./jun. 2000 
de oferecer uma programação muito atual à sua audiência e, repito, muito variada, amena e repetitiva, ainda que, claro, com muito mais meios econômicos do que a rádio brasileira.

Pelo exposto, pode-se concluir que a programação das duas emissoras internacionais alcançam, considerando suas limitações, o que propuseram em seus objetivos: a brasileira, divulgar as realizações do governo federal; e a espanhola, oferecer uma imagem atual da Espanha. Em resumo, Brasil e Espanha utilizam a radiodifusão internacional como suporte propagandístico de suas potencialidades como nações que procuram conquistar, através de uma imagem atraente e simpática, espaços e atenção entres os países da América do Sul, América Central e Estados Unidos.

\section{Abstract}

The present research draws a comparison between the programming and news of two international broadcasting stations - Radio Nacional do Brasil and Radio Exterior de Espanha -, aiming to confirm whether the similarities and differences in the structuration of their programming and in the contents of the news, have a ditect relation with their functions and communicative purposes.

Key words: radio, program, programming, radio news.

\section{Nota}

1. Quanto às zonas de cobertura, além da América do Sul, que recebe 17 horas por dia, a Rádio Exterior da Espanha transmite sua programação, através do Serviço Mundial em Espanhol, para a África Equatorial, América Central, América do Norte, Norte da América do Sul, Sul da América do Norte, Austrália, Europa, Filipinas, Japão, Magreb e Oriente Médio, totalizando 91 horas por dia. Além da programação na língua do país, a REE transmite seus programas em árabe, francês, inglês, alemão, português, e nas outras línguas da Espanha: catalão, basco e galego. Já a Rádio Nacional do Brasil, além da programação em espanhol para a América do Sul, em inglês para América do Norte e Europa, em português para Europa e África e em alemão para a Europa. Para as suas transmissões, a RNB utiliza 4 frequiências na faixas de 19 e 31 metros. A REE, por seu lado, utiliza 29 frequiências nas faixas de $13,16,19,25,31,41$ e 49 metros.

Comun. Inf., v. 3, n. 1, p. 13-26, jan./jun. 2000 


\section{Referêrcias}

CEBRIÁN HERREROS, Mariano. Géneros informativos audiovisuales. Madri: Ciência 3, 1992.

DUVERGER, Murice. Ciência política: teoria e método. Rio de Janeiro: Zahar, 1962.

FAUS BELAU, Angel. La radio: intruducción a un medio desconocido. Madri: Guardiana, 1974.

FONTCUBERTA, Mar de; VELÁZQUEZ, Teresa. La interpretación de la noticia periodística. In: - Métodos de análisis de la prensa: encuentros sobe metodología de análisis dela prensa (en torno al El País). Madri: Casa Velázquez, 1987.

HALE, Julian. La radio como arma política. Barcelona: Gustavo Gili, 1979.

KRIPPENDORFF, Klaus. Metodologías de análisis de contenido: teoría e práctica. Barcelona: Paidós, 1990.

MARTÍ i MARTÍ, Josep María. Modelos de programación radiofônica. Barcelona: Feed-Back, 1990.

MERAYO PÉREZ, Arturo. Para entender la radio: estructura del proceso informativo radiofônico. Salamanca: Publicaciones Universidad Pontificia, 1992. MOREIRA, Sônia Virgínia. O rádio no Brasil. Rio de Janeiro: Rio Fundo, 1991. NEWMAN, John F. Periodismo radiofônico. México: Limusa, 1991.

NÚNEZZ MAYO, Oscar. La radio sin fronteras: radiodifusión exterior e comunicación de masas. Pamplona: Universidad de Navarra, 1991.

PRADO, Emilio. Estrutura da informação radiofônica. São Paulo: Summus, 1985.

RODRIGO ALSINA, Miguel. La contrucción de la noticia. Barcelona: Paidós, 1989.

ROMAIS, Célio. O que é rádio em ondas curtas. São Paulo: Brasiliense, 1989. SWETLANA, Gisela Ortriwano. A informação no rádio: os grupos de poder e a determinação dos conteúdos. São Paulo: Summus, 1985.

VAN DIJK, Teun A. La noticia como discurso: comprensión, estructura y producción de la información. Barcelona: Paidós, 1985.

VILLAFAÑÉ, J.; BUSTAMANTE, E.; PRADO, E. Fabricar noticias: las rutinas productivas en radio y televisión. Barcelona: Mitre, 1985.

Comun. Inf., v. 3, n. 1, p. 13-26, jan./jun. 2000 